\title{
Changes in empathy among first year medical students before and after a medical humanities module
}

\author{
P. Ravi Shankar, Rano M Piryani \\ KIST Medical College, Nepal.
}

\section{ARTICLE INFO}

Received

$: 26 / 05 / 2012$

Accepted : :23/09/2012

Published : :01/03/2013

\section{KEYWORD}

Empathy

Interpersonal reactivity index

Medical humanities

Medical students

Nepal

\section{ABSTRACT}

Introduction: A medical humanities $(\mathrm{MH})$ module is conducted for all first year students at at KIST Medical College, Lalitpur, Nepal. Objective: The present study was conducted to measure empathy among students before and after a Medical Humanities (MH) module using Interpersonal Reactivity Index (IRI) a validated measure of empathy at KIST Medical College, Lalitpur, Nepal from February to May 2009. Method: IRI was administered to students before and on conclusion of the module. IRI measures four aspects of empathy: Perspective-taking (PT), Fantasy (FS), Empathic concern (EC) and Personal distress (PD). Students were invited to participate in the study. Demographic information (gender, method of financing of medical education, area of residence and occupations of parents) was collected. The pre-module and post-module scores were compared among different subgroups of respondents using appropriate nonparametric tests $(\mathrm{p}<0.05)$. Result: Sixty-four of the 75 students $(85.3 \%)$ participated in the survey pre-module and 57 students (76\%) post-module. Most were self-financing and from urban areas. Before the module the median (interquartile range) FS, PT, EC and PD scores were 20, 18 (15-20), $21(18.25-24)$ and 15 (10-18) respectively (maximum score 28 for each subscale). The PD score was significantly higher among females $(\mathrm{p}<0.001)$ and students whose father was not a doctor $(\mathrm{p}=0.049)$. After the module the median (interquartile range) FS, PT, EC and PD scores were 20 (15-24), 20 (17.5-22), 21 (17.5-23) and 16 (13-19) respectively. The PT score was significantly higher after the module $(\mathrm{p}=0.023)$. Conclusion: The module increased PT scores (cognitive empathy) in first year students. Follow up studies and studies in larger populations are required.

(c) Medical Education Department, School of Medical Sciences, Universiti Sains Malaysia. All rights reserved.

CORRESPONDING AUTHOR: P. Ravi Shankar, KIST Medical College, Nepal.

Email: ravi.dr.shankar@gmail.com 


\section{Introduction}

Helping physicians understand the patient's perspective and express caring, concern, and empathy towards patients are important educational objectives of medical schools. Empathy involves cognitive as well as affective or emotional domains [1]. The cognitive domain involves the ability to understand another person's inner experiences and feelings and to view the outside world from the other person's perspective [2]. The affective domain is the capacity to enter into or join the experiences and feelings of another person $[2,3]$.

Empathy enhances the doctor-patient relationship and improves both patient [4] and doctor satisfaction [5]. Studies have found a decline in empathy as students' progress through medical school. Diseker and Michielutte [6] observed a decrease in emotional empathy following clinical experiences among medical students. Bellini, Balme and Shea also have observed a decline in empathy among medical residents [7]. The decline has been a matter of concern to medical educators and interventional strategies to improve empathy have been developed. This decline has been compared to the 'battered child syndrome' and has been postulated to be due to inappropriate treatment of medical students [8]. The authors mentioned students underwent abusive treatment by faculty, residents and others and defined abuse as to treat in a harmful, injurious or offensive way, to attack in words; to speak harmfully, unjustly, and in an injurious manner about a person. The third year of medical school is regarded as especially important in this decline [9]. Lack of role models, large amount of material to learn, time pressure, patient and environmental factors and over reliance on technology has been postulated to be responsible.

Medical humanities (MH) is an interdisciplinary endeavour which uses the creative and intellectual strengths of different disciplines, including literature, art, creative writing, drama, film, music, philosophy, ethical decision making, anthropology and history to pursue medical educational goals [10]. MH has been stated to have an important role in education of future doctors with different modalities like literature, art, drama having specific benefits [11] including increase in empathy and compassion among doctors. In the United States (U.S.) medicinerelated poetry and prose were introduced in a third year family medicine clerkship [12]. Assessment suggested a positive influence on students in terms of empathy for the patients' perspective with a lesser impact on patient management. Student understanding of the patient's perspective became more detailed and complex after the intervention.

MH programs are uncommon in Nepal. A voluntary MH program had been conducted at Manipal College of Medical Sciences (MCOMS), Pokhara [13]. A MH module 'Sparshanam' has been conducted for first year medical students at KIST Medical College (KISTMC) affiliated to Institute of Medicine, Tribhuvan University (TU) [14]. Case scenarios, role-plays, paintings, debates were extensively used in the module. Empathy was measured both before and after the module. The MH module which has six activity-based sessions addressing various topics like empathy, the patient, the doctor, the doctor-patient relationship, the family and what it means to be sick in Nepal was the intervention. We did not have a control group as the Institutional Review Board (IRB) was of the opinion that it would not be proper to deprive students in the control group of the benefits of the module and we did not have sufficient resources to conduct another module for these students after the conclusion of the module. $\mathrm{MH}$ is a new discipline in Nepal and South Asia. Increase in empathy scores following a $\mathrm{MH}$ module could provide preliminary, indirect evidence for effectiveness of the module and can be used to plan further studies to strengthen the case for inclusion of $\mathrm{MH}$ in the curriculum.

The present study was carried out with the following objectives:

a. To compare the change in empathy among medical students following introduction of the module using the Interpersonal Reactivity Index (IRI) and 
b. To assess the differences in empathy total scores and subscale scores among different subgroups of respondents.

\section{Method}

KIST Medical College admitted its first batch of MBBS students in November 2008. A MH module is conducted for all first year medical students. In our institution the six basic science subjects of Anatomy, Physiology, Biochemistry, Pathology, Microbiology and Pharmacology are taught in an integrated organ-system based manner during the first two years. Early clinical contact is emphasized and students learn history taking skills in the first year where empathy and other interpersonal skills are important. Students also spend a month in rural and semi-urban communities to gain an understanding of family, societal, economic and other factors in health and disease.

The Interpersonal Reactivity Index (IRI) is used to measure empathy among individuals [15]. IRI is a validated instrument and has been previously used in a variety of settings to measure empathy. Higher scores indicate more empathy on the scoring system used. The perspective-taking (PT) scale, contains items which assess spontaneous attempts to adopt the perspectives of other people and see things from their point of view. Items on the fantasy (FS) scale measure the tendency to identify with characters in movies, novels, plays and other fictional situations. The empathic concern (EC) scale inquires about respondents' feelings of warmth, compassion, and concern for others, while the personal distress (PD) scale measures the personal feelings of anxiety and discomfort that result from observing negative experience of another person. The maximum score for each subscale is 28 .

A cross-sectional study using the IRI was conducted among students at the beginning of and conclusion of the $\mathrm{MH}$ module. Written informed consent was obtained from all students participating in the study. The self-administered questionnaire was administered twice; once before the start of the module and also immediately after the completion of the module. The questionnaire takes about 15 minutes to complete and students were instructed to submit their completed questionnaire within three days to the office assistant in the Program Coordinator's office. This was done so that students could complete the questionnaire at their leisure in a neutral environment. They were instructed not to discuss this with their peers but a certain exchange of ideas may have occurred but students were not aware about the scoring system and other methodological issues associated with the IRI. However, some of them may have looked up this information on the internet.

Demographic information (gender, method of financing of medical education, area of family residence and occupations of father and mother) was also collected. There was a set of 28 statements which respondents had to score according to how well it described them. The scale was from A (does not describe me well) to $\mathrm{E}$ (describes me very well). There was also a set of 20 statements and participants had to indicate their degree of agreement on a scale ranging from 1 (strongly disagree) to 7 (strongly agree). The scores in the four subscales were calculated and compared among different subgroups of respondents using appropriate non-parametric tests before and after the module. The scores did not follow a normal distribution on applying the one sample Kolmogorov-Smirnov test. Hence non-parametric tests were used for further analysis. The median subscale scores before and after the module was also compared using appropriate statistical tests. Mann-Whitney U test was used for demographic characteristics with two subgroups while Kruskal-Wallis test was used for occupation of mother in which there could be three categories: housewife, healthcare professional and other professions. We did not collect personal identifying information about the respondents and hence independent samples test (Mann-Whitney U test) was used for comparing scores before and after the module. A p value less than 0.05 was taken as statistically significant.

To ensure anonymity, names of students and identifying information were not collected. 


\section{Result}

Sixty-four of the 75 students (85.3\%) participated in the survey before the module and 51 students (68\%) after the module. Table 1 shows the demographic characteristics of respondents before and after the module. Most students were self-financing. Majority of students resided in urban areas and most did not have doctor parents.

Compared to pre-intervention, the postintervention scores increased after the module (Table 2). The PT scores significantly increased among male and female respondents after the module. PT scores increased significantly among self-financing students and among students whose mothers were housewives. There was no significant increase in other categories of scores. Pre-intervention the median (interquartile range) FS, PT, EC and PD scores were 20, 18 (15-20), 21 (18.25-24) and 15 (10-18) respectively. Table 3 compares the subscale scores among different subgroups of respondents before the module. The PD score was significantly higher among females ( $p<0.001)$ and among students whose father was not a doctor ( $\mathrm{p}=0.049)$.

Post-intervention the median (interquartile range) FS, PT, EC and PD scores were 20 (1524), 20 (17.5-22), 21 (17.5-23) and 16 (13-19) respectively. Table 4 compares the subscale scores among different subgroups of respondents after completion of the module. EC and PD scores were significantly higher among females compared to males $(\mathrm{p}=0.03, \mathrm{p}=0.016)$. The $\mathrm{PD}$ score was higher among respondents whose father was not a doctor ( $p=0.049)$. The PT score significantly increased after the module $(p=0.023)$. The PT score in females increased from 17 before the module to 20 post module ( $p$ $=0.009$ ). The median FS scores were 20 before and after the module. The median EC scores were 21 before and after the module while the PD scores increased from 15 to 16.

\section{Discussion}

The perspective taking scores in certain subgroups of respondents increased significantly after the module. Certain subscale scores were significantly different among certain subgroups of respondents both before and after the module.

Davis and coworkers have calculated means of the four subscales of IRI based on various studies for both males and females [15]. The mean FS scores for males and females were 15.73 and 18.75. The FS scores observed in this study were higher than those previously reported both before and after the module being 16.58 among males and 20.1 among females preintervention while the scores post-intervention were 18.3 among males and 21.2 among females [15]. Our scores for males were higher and for females lower. Mean EC scores observed were 19.04 (males) and 21.67 (females) [15]. Our scores among both males and females were higher. The PD scores were 9.46 and 12.28 for males and females respectively. Our scores were much higher and greater among females. We had used median and interquartile range instead of mean and standard deviation as the values were not following a normal distribution and the IRI uses a Likert-type scale. Median and interquartile range are suggested measures of central tendency and variation for Likert-type scales [16].

In the U.S. empathy was measured among medical students in the state of Minnesota using IRI [17]. The authors had used the PT and the EC subscales as measures of cognitive and emotive domains of empathy. Their PT scores were 19.5 for males and 21 for females. The score among males was comparable to ours while the score among females was higher. Their EC subscale scores were 21.1 and 24.1. The scores among males were comparable to ours but their scores among female students were higher. No differences in scores were observed over the four years of medical school. Evans and coworkers had measured empathy using IRI in 55 students in the first clinical year before and after a module on communication skills taught using lectures and workshop [18]. In the U.S. students enter medical school after completing a graduate course of study and are more mature and have more life experiences compared to our students. No significant change in IRI was observed. 
In the US a study using Jefferson Scale of Physician Empathy (JSPE) showed empathy in medical students was related to gender, students' interest in people oriented specialties, higher level of satisfaction with early maternal relationships, higher sociability and lower aggressive-hostility scores [19].

The $\mathrm{MH}$ module in our study had significantly increased the cognitive domain of empathy (PT) while the emotional domain did not change among our students. The module used a number of activities and situations which required participants to put themselves in the position of another person/s and see things from their perspective. Interpreting and exploring situations through role-plays, exploring and interpreting paintings through stories and role-plays were effective in helping students to see and understand things from the perspective of others. We believe this will be useful to them to understand the patient's perspective of sickness and disease. The empathic concern scale was quite high to begin with. Explanation for why the respondents' feelings of concern for others did not change is not possible with the available findings. We are unable to explain why respondents' feelings of concern for others did not increase while they were able to see things from their perspective. A possible reason could be the overemphasis on science and neglect of emotions during school in Nepal. All students are from a science background. The PT and EC scores are especially important for students.

Most of the studies on empathy and interpersonal skills have been carried out in a Western culture, especially in the U.S. context. In comparison to U.S., in Nepal students are only from a science background (in Nepal and many other countries only students with the subjects of Biology, Physics and Chemistry during the last two years of schooling can take up medicine), are younger and lectures are the major instructional methodology. $\mathrm{MH}$ is not a formally recognized part of the curriculum.

The study is among the few measuring changes in student empathy among medical students after a medical humanities module using a previously validated instrument. The study had limitations. Students with a greater interest in empathy and learning about interpersonal relationships are more likely to have participated in the study. Fewer students participated in the post-module survey. This could have been due to decreased attendance and interest because of course exams. This could have influenced the results. There was no control group as mentioned in the Introduction which could have weakened the methodological rigour of the study. The confounding effect of other modules and clinical posting on empathy was not excluded in the present study. The version of IRI used was the western one. Nepalese versions of IRI are not available and the authors did not adapt the instrument to a Nepalese context which may have biased the results.

\section{Conclusion}

This manuscript offers evidence that empathy scores among participants were higher after a medical humanities module. Modifications to improve empathic concern of participants may be required. Longitudinal follow up of participants is needed to examine whether the increase is sustained. Participants should also be observed during the clinical years of training to observe whether they show more empathic behaviour towards patients. At present other medical schools in the country do not offer a $\mathrm{MH}$ module so empathy levels before and after a $\mathrm{MH}$ module cannot be studied elsewhere in the country.

\section{Reference}

1. Davis MH. Empathy: A Social Psychological Approach. Madison: Wis, Brown and Benchmark; 1994

2. Hojat M, Mangione S, Nasca TJ, Cohen MJM, Gonnella JS, Erdmann JB, Veloski JJ et al. The Jefferson Scale of Empathy: development and preliminary psychometric data. Educ Psychol Meas. 2001;61:349-65

3. Aring CD. Sympathy and empathy. JAMA. 1958;167:448-52

4. Levinson W, Gorawa-Bhat, Lamb J. A study of patient clues and physician 
responses in primary care and surgical settings. JAMA 2000; 284: 1021-7.

5. Suchman AL, Roter D, Green M, Lipkin M Jr. Physician satisfaction with primary care office visits. Collaborative Study Group of the American Academy on Physician and Patient. Med Care. 1993;31:1083-92.

6. Diseker RA, Michielutte R. An analysis of empathy in medical students before and following clinical experiences. J Med Educ. 1981;56:1004-10.

7. Bellini LM, Baime M, Shea JA. Variation of mood and empathy during internship. JAMA. 2002;287:3143-6.

8. Silver HK, Glicken AD. Medical student abuse: Incidence, severity, and significance. JAMA. 1990;263:527532.

9. Hojat M, Vergare MJ, Maxwell K, Brainard G, Herrine SK, Isenberg GA, Veloski J, Gonnella GS. The devil is in the third year: A longitudinal study of erosion of empathy in medicals school. Acad Med. 2009;84:1182-91.

10. Kirklin D. The centre for medical humanities, Royal free and University College Medical School, London, England. Acad Med. 2003;78:1048-53.

11. Macnaughton J. The humanities in medical education: context, outcomes and structures. Med Humanit. 2000;26:23-30.

12. Shapiro J, Duke A, Boker J, Ahearn CS. Just a spoonful of humanities makes the medicine go down: introducing literature into a family medicine clerkship. Med Educ. 2005;39:605-12.

13. Shankar PR. A voluntary medical humanities module in a medical college in Western Nepal: participant feedback. Teach Learn Med. 2009;21:248-53..

14. Shankar PR, Piryani RM, Thapa TP, Karki BMS. Our Experiences With 'Sparshanam', A Medical Humanities Module For Medical Students At KIST Medical College, Nepal. Journal of Clinical and Diagnostic Research 2010: 4: 2158-2162.

15. Davis MH. A multidimensional approach to individual differences in empathy. JSAS Catalog of Selected Documents in Psychology, 1980; 10: 85. Available from: http://www.uv.es/ friasnav/Davis_1980. pdf.

16. Jamieson S. Likert scales: how to (ab)use them. Med Educ. 2004;38:12178.

17. Thomas MR, Dyrbye LN, Huntington JL, Lawson KL, Novotny PJ, Sloan JA, Shanafelt TD. How do distress and wellbeing relate to medical student empathy? A multicenter study. J Gen Intern Med 2007;22:177-83.

18. Evans BJ, Stanley RO, Burrows GD. Measuring medical students' empathy skills. Br J Med Psychol. 1993;66:12133.

19. Hojat M, Zuckerman M, Magee M, Mangione S, Nasca T, Vergare $M$, Gonnella JS. Empathy in medical students as related to specialty interest, personality and perceptions of mother and father. Pers Individ Dif. 2005;39:1205-15. 
Table 1: Demographic characteristics of student respondents (before and after the module) ${ }^{*}$

\begin{tabular}{|lll|}
\hline Characteristics & $\begin{array}{l}\text { Pre-module group (N= 64) } \\
\text { n (\%) }\end{array}$ & $\begin{array}{l}\text { Post-module group (N =51) } \\
\mathbf{n}(\%)\end{array}$ \\
\hline $\begin{array}{l}\text { Gender } \\
\text { Male }\end{array}$ & $38(59.4)$ & $28(54.9)$ \\
Female & $21(32.8)$ & $21(41.2)$ \\
$\begin{array}{l}\text { Financing } \\
\text { Scholarship }\end{array}$ & $1(2.0)$ \\
Self-financing & $1(1.6)$ & $50(98.0)$ \\
Area of family residence & $57(89.1)$ & $43(84.3)$ \\
Urban & $52(81.3)$ & $8(15.7)$ \\
$\begin{array}{l}\text { Occupal } \\
\text { Doctor }\end{array}$ & $6(9.4)$ & $3(5.9)$ \\
$\begin{array}{l}\text { Others } \\
\text { Occupation of mother }\end{array}$ & $6(9.4)$ & $41(80.4)$ \\
Doctor & $55(85.9)$ & $1(2)$ \\
$\begin{array}{l}\text { Others } \\
\text { Housewife }\end{array}$ & $3(4.7)$ & $15(29.4)$ \\
\end{tabular}

* In certain subgroups the total score may be less than the sample size as certain respondents did not fill in the required demographic characteristics

Table 2: Median subscale scores among different categories of respondents before and after the module*

\begin{tabular}{|c|c|c|c|c|c|c|c|c|c|c|c|c|}
\hline \multirow[t]{3}{*}{ Characteristics } & \multicolumn{12}{|c|}{ Median scores } \\
\hline & \multicolumn{3}{|c|}{ Perspective-taking } & \multicolumn{2}{|c|}{ Fantasy } & & \multicolumn{3}{|c|}{ Empathetic concern } & \multicolumn{3}{|c|}{ Personal distress } \\
\hline & Pre & Post & p-value & Pre & Post & p-value & Pre & Post & p-value & Pre & Post & p-value \\
\hline \multicolumn{13}{|l|}{ Gender } \\
\hline Male & 19 & 20 & 0.037 & 18.5 & 20 & 0.289 & 21 & 20 & 0.475 & 14 & 15 & 0.066 \\
\hline Female & 17 & 20 & 0.009 & 20 & 20 & 0.545 & 21 & 22 & 0.919 & 18 & 18 & 0.658 \\
\hline \multicolumn{13}{|l|}{ Financing } \\
\hline Scholarship* & 13 & 14 & & 18 & 17 & & 14 & 17 & & 15 & 13 & \\
\hline Self-financing & 18 & 20 & 0.001 & 20 & 19.5 & 0.302 & 21 & 21 & 0.758 & 14 & 17 & 0.054 \\
\hline \multicolumn{13}{|l|}{$\begin{array}{l}\text { Place of } \\
\text { Residence }\end{array}$} \\
\hline Urban & 18 & 18 & 0.984 & 20 & 22 & 0.063 & 21 & 21 & 0.795 & 14.5 & 14.5 & 0.924 \\
\hline Rural & 15 & 15 & 0.606 & 20.5 & 18 & 0.701 & 21 & 21 & 0.810 & 15 & 15 & 0.918 \\
\hline \multicolumn{13}{|l|}{ Occupation of } \\
\hline Doctor & 18 & 18 & 0.928 & 22 & 22 & 0.928 & 20.5 & 20.5 & 0.841 & 9 & 9 & \\
\hline Others & 18 & 20 & 0.001 & 19 & 19 & 0.202 & 21 & 21 & 0.541 & 15 & 15 & 0.992 \\
\hline \multicolumn{13}{|l|}{$\begin{array}{l}\text { Occupation of } \\
\text { mother }\end{array}$} \\
\hline Doctor & 20 & 20 & 0.700 & 20 & 20 & 0.998 & 20 & 20 & 0.400 & 14 & 14 & 0.980 \\
\hline Others & 17.5 & 17.5 & 0.318 & 20 & 19 & 0.613 & 21 & 21 & 0.709 & 15 & 16 & 0.660 \\
\hline Housewife & 16 & 18 & 0.001 & 19 & 19 & 0.448 & 21 & 21 & 0.874 & 15 & 15 & 0350 \\
\hline
\end{tabular}


Table 3: Median subscale scores among different categories of respondents before the module (n=64)

\begin{tabular}{|c|c|c|c|c|}
\hline \multirow[b]{2}{*}{ Characteristics } & \multicolumn{4}{|c|}{ Median scores } \\
\hline & Perspective-taking & Fantasy & Empathic concern & Personal Distress \\
\hline \multicolumn{5}{|l|}{ Gender } \\
\hline Male & 19 & 18.5 & 21 & 14 \\
\hline Female & 17 & 20 & 21 & 18 \\
\hline p-value & 0.069 & 0.085 & 0.2 & $<0.001$ \\
\hline \multicolumn{5}{|l|}{ Area of family } \\
\hline \multicolumn{5}{|l|}{ Residence } \\
\hline Urban & 18 & 20 & 21 & 14.5 \\
\hline Rural & 15 & 20.5 & 21 & 15 \\
\hline p-value & 0.194 & 0.592 & 0.891 & 0.756 \\
\hline \multicolumn{5}{|l|}{$\begin{array}{l}\text { Occupation of } \\
\text { Father }\end{array}$} \\
\hline Doctor & 18 & 22 & 20.5 & 9 \\
\hline Others & 18 & 19 & 21 & 15 \\
\hline p-value & 0.768 & 0.323 & 0.953 & 0.049 \\
\hline \multicolumn{5}{|l|}{$\begin{array}{l}\text { Occupation of } \\
\text { Mother }\end{array}$} \\
\hline Doctor & 20 & 20 & 20 & 14 \\
\hline Others & 17.5 & 20 & 21 & 15 \\
\hline Housewife & 17 & 19 & 21 & 15 \\
\hline p-value & 0.534 & 0.842 & 0.958 & 0.769 \\
\hline
\end{tabular}

Table 4: Median subscale scores among different categories of respondents after the module ( $\mathrm{n}=51$ )

\begin{tabular}{|c|c|c|c|c|}
\hline \multirow[b]{2}{*}{ Characteristics } & \multicolumn{4}{|c|}{ Median scores } \\
\hline & Perspective-taking & Fantasy & Empathic concern & Personal Distress \\
\hline \multicolumn{5}{|l|}{ Gender } \\
\hline Male & 20 & 20 & 20 & 15 \\
\hline Female & 20 & 20 & 22 & 18 \\
\hline p-value & 0.625 & 0.085 & 0.03 & 0.016 \\
\hline \multicolumn{5}{|l|}{ Financing } \\
\hline Scholarship & 19 & 20 & 19 & 15 \\
\hline Self-financing & 20 & 19.5 & 21 & 17 \\
\hline p-value & 0.244 & 0.803 & 0.527 & 0.144 \\
\hline \multicolumn{5}{|l|}{$\begin{array}{l}\text { Area of family } \\
\text { Residence }\end{array}$} \\
\hline Urban & 18 & 22 & 21 & 14.5 \\
\hline Rural & 15 & 18 & 21 & 15 \\
\hline p-value & 0.244 & 0.803 & 0.527 & 0.756 \\
\hline \multicolumn{5}{|l|}{$\begin{array}{l}\text { Occupation of } \\
\text { Father }\end{array}$} \\
\hline Doctor & 18 & 22 & 20.5 & 9 \\
\hline Others & 20 & 19 & 21 & 15 \\
\hline p-value & 0.768 & 0.323 & 0.953 & 0.049 \\
\hline \multicolumn{5}{|l|}{$\begin{array}{l}\text { Occupation of } \\
\text { Mother }\end{array}$} \\
\hline Doctor & 20 & 20 & 20 & 14 \\
\hline Others & 17.5 & 20 & 21 & 15 \\
\hline Housewife & 17 & 19 & 21 & 15 \\
\hline p-value & 0.534 & 0.842 & 0.958 & 0.769 \\
\hline
\end{tabular}

